\title{
Mapping Interactions Within the Evolving Science of Science and Innovation Policy Community
}

\author{
Angela M. Zoss and Katy Börner \\ \{amzoss,katy\}@indiana.edu \\ Cyberinfrastructure for Network Science Center, School of Library and Information Science \\ Indiana University, 1320 E. 10th Street, Bloomington, IN 47405
}

\begin{abstract}
The Science of Science \& Innovation Policy (SciSIP) program at the National Science Foundation (NSF) supports research designed to advance the scientific basis of science and innovation policy. The program was established at NSF in 2005 in response to a call from Dr. John Marburger III, then science advisor to the U.S. President, for a "science" of science policy. It has co-funded 162 awards that aim to develop, improve, and expand data, analytical tools, and models that can be directly applied in the science policy decision making process. The long-term goals of the SciSIP program are to provide a scientifically rigorous and quantitative basis for science policy and to establish an international community of practice. The program has an active listserv that, as of January 2011, has almost 700 members from academia, government, and industry.

This study analyzed all SciSIP awards (through January 2011) to identify existing collaboration networks and co-funding relations between SciSIP and other areas of science. In addition, listserv data was downloaded and analyzed to derive complementary discourse information. Key results include evidence of rich diversity in communication and funding networks and effective strategies for interlinking researcher and science policy makers, prompting discussion, and resource sharing.
\end{abstract}

\section{Introduction}

Burgeoning research fields depend on a solid scientific and resource foundation as well as an active community for success and development. The early phases of a new area of interest offer an opportunity to identify the key research teams, foundational research works, and communication patterns that influence the growth of the field. While publications and funding awards hint at the structure of the field that will be, publication and citation time delays lead to data sparseness in the early years. Just as the research within the field will evolve over time, the associations to and influence from external research will also change. Other indicators of interaction, such as engagement in scholarly discourse venues, can provide a richer picture of activity in the field and complement traditional network analyses to map the structure of younger fields of research.

This paper follows in the tradition of earlier attempts to visualize online communities (Donath, Karahalios, \& Viegas, 1999; Welser, Gleave, Fisher, \& Smith, 2007; Xiong \& Donath, 1999) and begins the work of mapping the emerging field of Science of Science and Innovation Policy (SciSIP) research by combining traditional bibliometric methods with content analysis of a less formal scholarly communication venue: the listserv associated with the NSF SciSIP program ("Science of Science and Innovation Policy," 2010). Analyzing discourse can highlight both the roles of individual community members and the patterns of solicitation and response that guide interaction. These may offer insights into the growth of the community unavailable by other methods.

\section{Research Questions}

This research is informed by the following research questions:

- What interactions are made visible by analysis of formal communication channels like awards and publications?

- How can analysis of informal communication supplement traditional analysis techniques? 
- What roles do researchers play in the various interaction networks?

In this study, traditional network analysis techniques are used to analyze funding, collaboration, and communication networks, each of which operationalize a type of interaction relevant to the SciSIP community. These methods are contextualized by and layered with the results of a content analysis that examines communication strategies and evaluates their effectiveness.

\section{Methods}

The network analyses presented here use award and publication data from the NSF Science of Science and Innovation Policy program downloaded from NSF's Award Search site ("National Science Foundation Award Search," 2008). The email messages used for the content analysis were sent to the SciSIP listserv (scisip@lists.nsf.gov) between January 1, 2009 and December 31, 2010 (24 months).

\section{Award and Publication Data}

Quantitative analysis of the SciSIP award data began by preparing the award and publication data collected from the NSF award search site. A search performed by looking up the "Science of Science Policy" program (i.e., those awards with program element code “7626”) on December 17, 2010 resulted in 162 active and expired awards. The award metadata for these results were downloaded in Excel format. Within the results page, each award number is linked to the award's abstract page on the NSF site. Of the 162 awards, 22 of the abstract pages advertise publications that have resulted from the award, and these references were collected and associated with the award metadata for these awards. A total of 56 unique publications ${ }^{1}$ were found for the 22 awards. Publication data are summarized in Table 1.

Table 1. Publication data, subdivided by start date of award and date of publication.

\begin{tabular}{|c|c|c|c|c|c|}
\hline & \multicolumn{4}{|c|}{ Award Start Date in } \\
\hline & & 2006 & 2007 & 2008 & 2009 \\
\hline \multicolumn{2}{|c|}{ Number of Awards: } & 2 & 5 & 13 & 2 \\
\hline \multirow{4}{*}{ 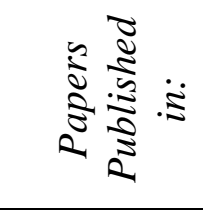 } & 2007 & 4 & 3 & 1 & 0 \\
\hline & 2008 & 5 & 1 & 8 & 0 \\
\hline & 2009 & 1 & 2 & 14 & 2 \\
\hline & 2010 & 0 & 3 & 11 & 1 \\
\hline
\end{tabular}

Award and publication metadata were processed to normalize the names of investigators and authors for the collaboration networks. Award amounts were split evenly among investigators and funding programs in determining the normalized amount of funding received or distributed. Individuals were also cross-referenced with members of the listserv to determine how many investigators and authors were also captured within our participant list for the SciSIP listserv. Networks were generated and analyzed using the $\mathrm{Sci}^{2}$ Tool $\left(\mathrm{Sci}^{2} \mathrm{Team}, 2009\right.$; Weingart, et al., 2010).

\section{Listserv Data}

Content analysis began by preparing the data collected from the SciSIP listserv. Because the community of practice includes both those who send messages to the listserv and those who

\footnotetext{
${ }^{1}$ While these data are certainly incomplete, the extent is not clear. The publications found include papers from 2010, but the publication information for each award may still be incomplete. Likewise, many of the awards without publication information likely have publications that have not yet been added to the abstract pages.
} 
subscribe but do not actively participate in discussion, the roster of subscribers was retrieved from the listserv. As of January 21, 2010, the SciSIP listserv had 475 "normal” members (where "normal" is the default membership type given by the listserv program). A follow-up request on December 18, 2010 showed 659 members. An additional request on January 10, 2011 to examine continued growth showed 674 members.

These membership rosters were compared, normalized, and combined with the list of message senders to capture as large of a snapshot of the community as possible. For example, senders were matched to registered emails where possible, but they were retained even if they did not appear on any of the subscription lists. The full list of normalized participants with connections to the listserv used for this study comprises 728 individuals. This snapshot is almost certainly a subset of the individuals who have ever subscribed to the listserv, but it is likely to be a large and representative sample of the membership of the list, given the relative youth of the list and the low attrition rate of membership. (Only 36 of the 475 members from January 2010 - less than 8\% - had left the list by December 2010, and the January 2011 list showed a loss of only 2 additional members from the December list.)

The full membership list of 728 individuals was analyzed for institutional affiliation and country to provide descriptive context for the discussions that take place on the listserv. That is, each individual was associated to a type of institution based on email address or public employment information. Institutional affiliations (across countries) were normalized to the following four types, inspired by standard email top-level domains: commercial $\left(\mathrm{com}^{+}\right)$, educational (edu+), government (gov + ), or non-profit organization (org + ). For example, any independent, non-profit organization from any country was coded as "org+", regardless of the domain used by the organization. All government agencies or departments were coded as "gov+" (as were the small number of ".mil" and ".us" addresses). The "com+" code includes both individuals that were confirmed to be working for a commercial company and those using free email services that could not otherwise be associated with an institution. Summaries of the affiliations and countries of origin can be seen in Tables 2 and 3, respectively. (The 24 countries with fewer than three senders are omitted.)

Table 2. Normalized institutional affiliations for participants on the SciSIP listserv (both the full list of readers and those who sent messages).

\begin{tabular}{l|cc}
\hline & Full List & Senders \\
\hline com+ & $96(13 \%)$ & $14(7 \%)$ \\
edu+ & $284(39 \%)$ & $94(47 \%)$ \\
gov $^{+}$ & $250(34 \%)$ & $66(33 \%)$ \\
org+ & $98(13 \%)$ & $25(13 \%)$ \\
Total & $728(100 \%)$ & $199(100 \%)$ \\
\hline
\end{tabular}

Table 3. Top 6 normalized countries of origin for participants on the SciSIP listserv (both the full list of readers and those who sent messages).

\begin{tabular}{l|cc}
\hline & Full List & Senders \\
\hline us & $608(83.52 \%)$ & $167(83.92 \%)$ \\
uk & $27(3.71 \%)$ & $10(5.03 \%)$ \\
se & $20(2.75 \%)$ & $3(1.51 \%)$ \\
ca & $15(2.06 \%)$ & $3(1.51 \%)$ \\
au & $6(0.82 \%)$ & $3(1.51 \%)$ \\
nl & $4(0.55 \%)$ & $3(1.51 \%)$ \\
(24 omitted) & $\ldots$ & $\ldots$ \\
\hline
\end{tabular}




\begin{tabular}{l|ll}
\hline Total & $728(100 \%)$ & $199(100 \%)$ \\
\hline
\end{tabular}

The entire corpus of email messages to the SciSIP listserv (as of January 4, 2011) was downloaded, cleaned, and coded for this project. The corpus includes 919 messages from 199 individual senders (or almost $27 \%$ of the aggregated membership list of 728 ). Message distribution across senders can be seen in Figure 1. Raw values and logarithmic binning (Milojević, 2010) emphasize that a majority of senders send only a single message.

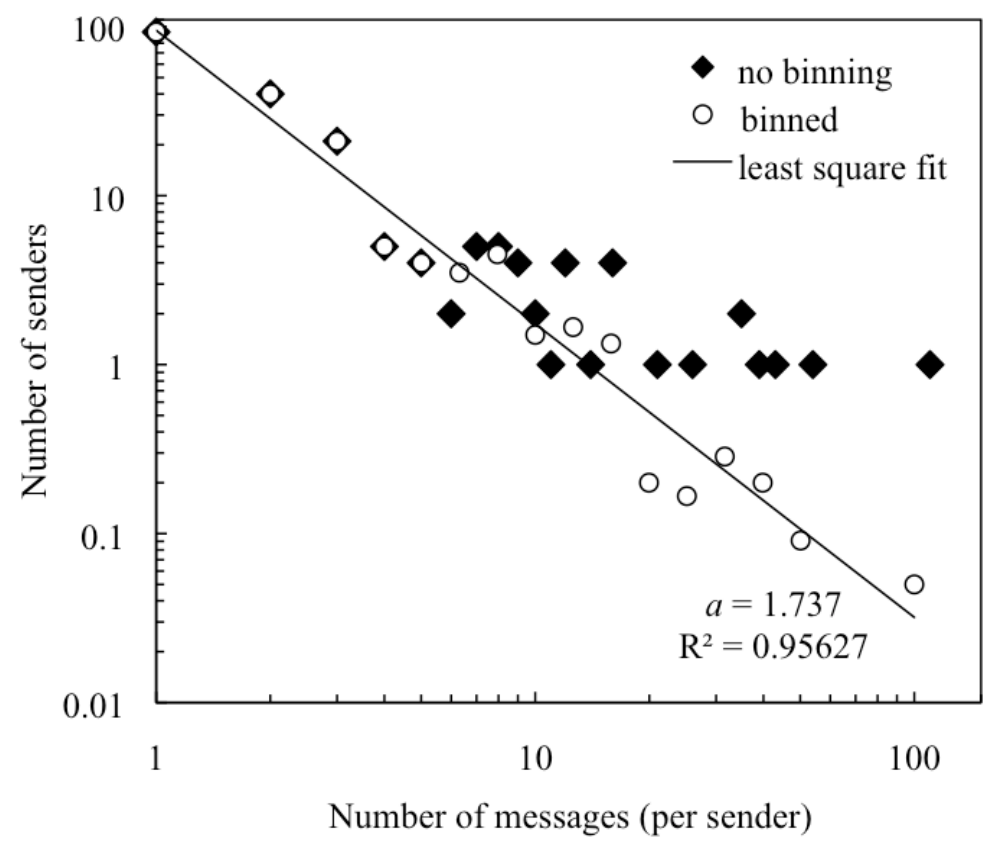

Figure 1. Distribution of messages across senders, with raw and binned (Milojević, 2010) values.

Messages were compiled in a format appropriate for analysis by using Microsoft Outlook and Access, both of which have the capability to convert emails to a tabular format. Of the 919 messages, two contained content that was unreadable because of text encoding problems. The header information for these two messages is included in thread analysis, but as the message content cannot be deciphered, the two messages are excluded from content analysis.

\section{Results}

\section{Funding and Publication Activity}

Traditional bibliometric analyses might utilize funding and publication data similar to the data set that has been prepared for SciSIP awards. These data are often taken as indicators of collaboration, interdisciplinarity, productivity, and impact. For example, interdisciplinarity might be studied by examining the department affiliations of Principal Investigators or the publication outlets of the papers that have been produced by an award. Productivity might be operationalized as the volume of papers or patents produced by an award. These measures, however, are highly sensitive to the availability of data, the duration of an award, the amount awarded, and the time that has elapsed since the start date of the award. With a program that has only been in operation for a short time, these metrics will be unavailable or unreliable. The few data points that do exist for the SciSIP program, however, may hint at the structure of the field as it emerges from multiple domains of science.

The top ten of the 162 SciSIP awards by dollar amount are summarized in Table 4. The highest award amounts are dominated by longer contracts that are co-funded by other programs. When the top ten are excluded, the remaining awards - primarily standard grants - 
are of shorter duration (2.49 years on average) and have received smaller award amounts to date (approximately $\$ 235,000$ on average). 
Table 4. The top ten highest funded SciSIP awards.

\begin{tabular}{|c|c|c|c|c|}
\hline Subject & Program(s) & $\begin{array}{c}\text { Award } \\
\text { Instrument }\end{array}$ & $\begin{array}{l}\text { Length of Award } \\
\text { (in Years) }\end{array}$ & $\begin{array}{c}\text { Awarded } \\
\text { Amount }\end{array}$ \\
\hline $\begin{array}{l}\text { CY2002 NSF/Census Interagency Agreement for } \\
\text { Survey of Industrial Research and Development }\end{array}$ & $\begin{array}{l}\text { Research \& Development Statist; Science Resources } \\
\text { Statistics; SRS Survey; Science of Science Policy }\end{array}$ & $\begin{array}{c}\text { Contract } \\
\text { Interagency } \\
\text { Agreement }\end{array}$ & 13 & $\$ 22,270,724$ \\
\hline $\begin{array}{l}\text { Research, Redesign and Conduct the Survey of } \\
\text { Graduate Students and Postdoctorates in Science } \\
\text { \& Engineering (GSS) Fall 2007, 2008, and } 2009\end{array}$ & $\begin{array}{l}\text { Human Resources Statistics PGM; Science Resources } \\
\text { Statistics; Science of Science Policy }\end{array}$ & Contract & 5 & $\$ 7,525,243$ \\
\hline Data on Scientific Publications & $\begin{array}{l}\text { Human Resources Statistics PGM; Science \& } \\
\text { Engineering Indicators; Science Resources Statistics; } \\
\text { SRS Survey; Science of Science Policy }\end{array}$ & Contract & 5 & $\$ 7,309,767$ \\
\hline $\begin{array}{l}\text { Redesign of the Survey of Research and } \\
\text { Development Expenditures at Universities and } \\
\text { Colleges }\end{array}$ & $\begin{array}{l}\text { Research \& Development Statist; Science of Science } \\
\text { Policy }\end{array}$ & Contract & 3 & $\$ 1,999,483$ \\
\hline $\begin{array}{l}\text { Producing a BEA/NSF Research and } \\
\text { Devlopment Satellite Account }\end{array}$ & $\begin{array}{l}\text { Research \& Development Statist; Science Resources } \\
\text { Statistics; SRS Survey; Science of Science Policy }\end{array}$ & $\begin{array}{c}\text { Contract } \\
\text { Interagency } \\
\text { Agreement }\end{array}$ & 7 & $\$ 1,820,000$ \\
\hline $\begin{array}{l}\text { Technical Proposal to Conduct Phase 2: Postdoc } \\
\text { Data Project }\end{array}$ & $\begin{array}{l}\text { Science Resources Statistics; SRS Survey; Science of } \\
\text { Science Policy }\end{array}$ & Contract & 3 & $\$ 1,583,571$ \\
\hline $\begin{array}{l}\text { A National Survey of Organizations to Study } \\
\text { Globalization, Innovation and Employment }\end{array}$ & $\begin{array}{l}\text { Science of Science Policy; Innovation \& Org Sciences } \\
\text { (IOS); Sociology }\end{array}$ & Standard Grant & 3 & $\$ 1,012,496$ \\
\hline $\begin{array}{l}\text { Management and Organizational Practices } \\
\text { Across the US }\end{array}$ & $\begin{array}{l}\text { Science of Science Policy; Innovation \& Org Sciences } \\
\text { (IOS); Decision Risk \& Management Sci; Economics }\end{array}$ & Standard Grant & 2 & $\$ 794,878$ \\
\hline $\begin{array}{l}\text { DAT: A Visual Analytics Approach to Science } \\
\text { and Innovation Policy }\end{array}$ & Science of Science Policy & Standard Grant & 3 & $\$ 746,571$ \\
\hline $\begin{array}{l}\text { TLS: Science \& Technology Innovation Concept } \\
\text { Knowledge-base (STICK): Monitoring, } \\
\text { Understanding, and Advancing the (R)Evolution } \\
\text { of Science \& Technology Innovations }\end{array}$ & Science of Science Policy & Standard Grant & 3 & $\$ 718,644$ \\
\hline
\end{tabular}


Interestingly, many of the SciSIP awards are co-funded by other NSF directorates. The cofunding network in Figure 2 shows particularly strong ties between SciSIP and Economics; Science, Technology and Society; and Innovation \& Organizational Sciences (IOS). None of the 41 programs in the network has co-funded more than 12 awards with SciSIP, suggesting that the collaborations between SciSIP and other programs are widely distributed. (The shade of the nodes represents the sum of the normalized awarded amounts; awarded amounts were divided evenly among the co-funding programs for each award. The size of the node represents the number of awards co-funded by the program, and the size of the edges represents the number of awards shared by the two programs.)

\section{Co-Funding Network}

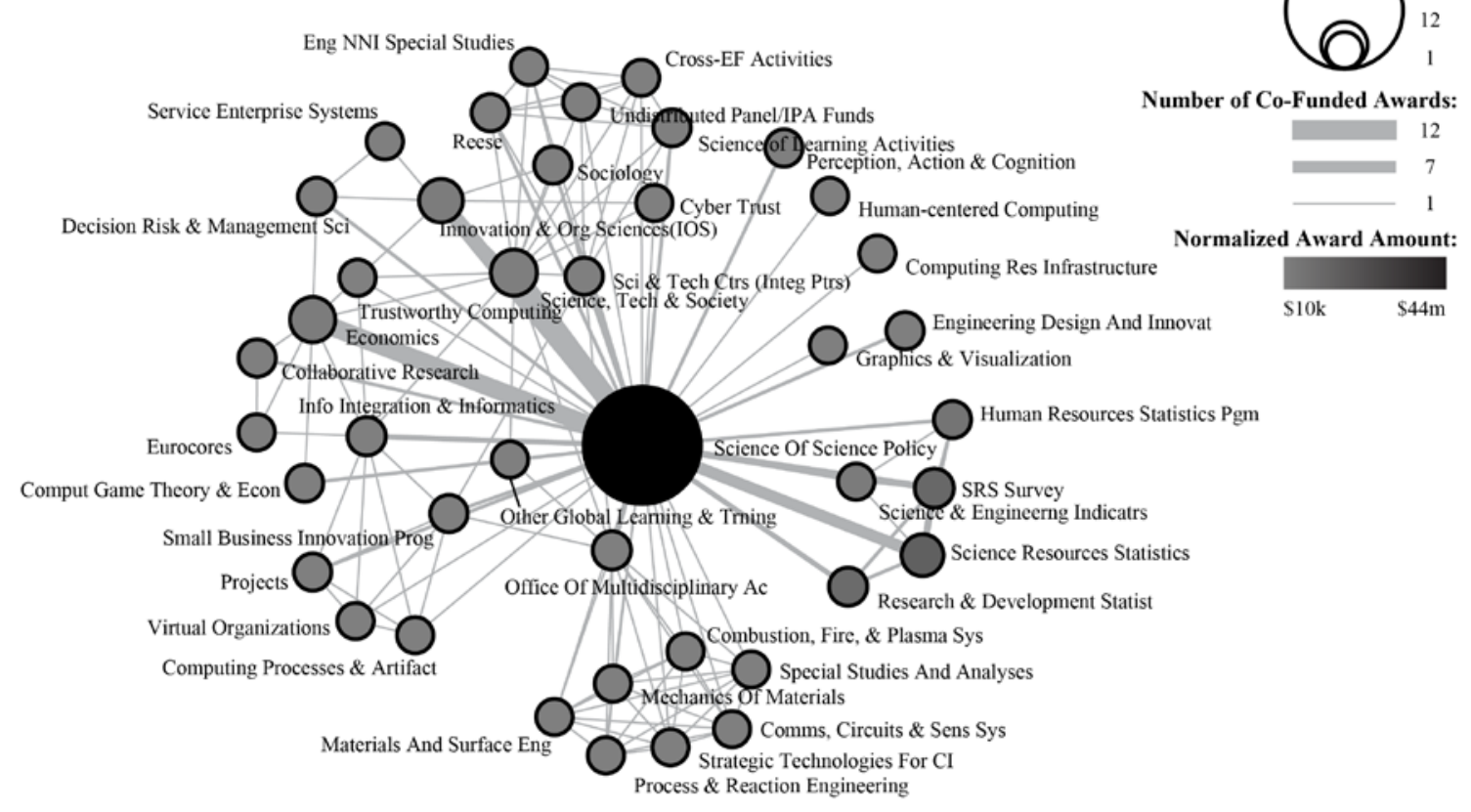

Figure 2. Network of programs that co-fund SciSIP awards.

The co-funding network shows how the SciSIP program is situated within the larger funding landscape and how it relates to other fields of interest. Collaboration networks such as co-PI and co-author networks can instead be used to represent the interconnectedness within a community or field. In the case of SciSIP, an investigator (either as Primary Investigator or co-PI) rarely received multiple awards within this four-year time frame, though investigators do occasionally obtain additional funding for a workshop through a separate award. As a result, the co-PI network for SciSIP awards is largely unconnected. There are 236 investigators (including both PIs and co-PIs) in the network. The network has 133 components, including 71 isolated nodes. The 165 connected investigators are thus distributed over 62 components, for an average of only 2.66 investigators for each of these components. The density of the network is 0.0055 . Rather than taking this low density as an indication that investigators do not collaborate, the network suggests that the SciSIP funding mechanism is successfully distributing funding across many different collaborative groups.

The preliminary publication data collected can be used to supplement award data and show additional collaborations. Excluding the awards that had no publication data, there are 22 awards associated with 56 publications. The 123 investigators and authors associated with these awards and publications are visualized in Figure 3. The relationship between two individuals is given by the color of the edge between the nodes. Individuals with a co-PI relationship have a yellow edge. Those with a co-author relationship have a blue edge. Edges 
that denote both relationships have the resulting mixture color: green. Nodes are size-coded by the number of combined awards and papers for which they appear as a collaborator.

The individuals also have a colored outline to indicate whether or not they appear among the 728 identified listserv participants. Of the 123 nodes in the collaboration network, 20 (16.2\%) also participate on the listserv. (Among all 139 PIs, 37 (26.6\%) are listserv participants.) Most of the listserv participants in the network have edu+ affiliations, as might be expected among award recipients.

\section{Collaboration Network}

Combined Awards and Papers:
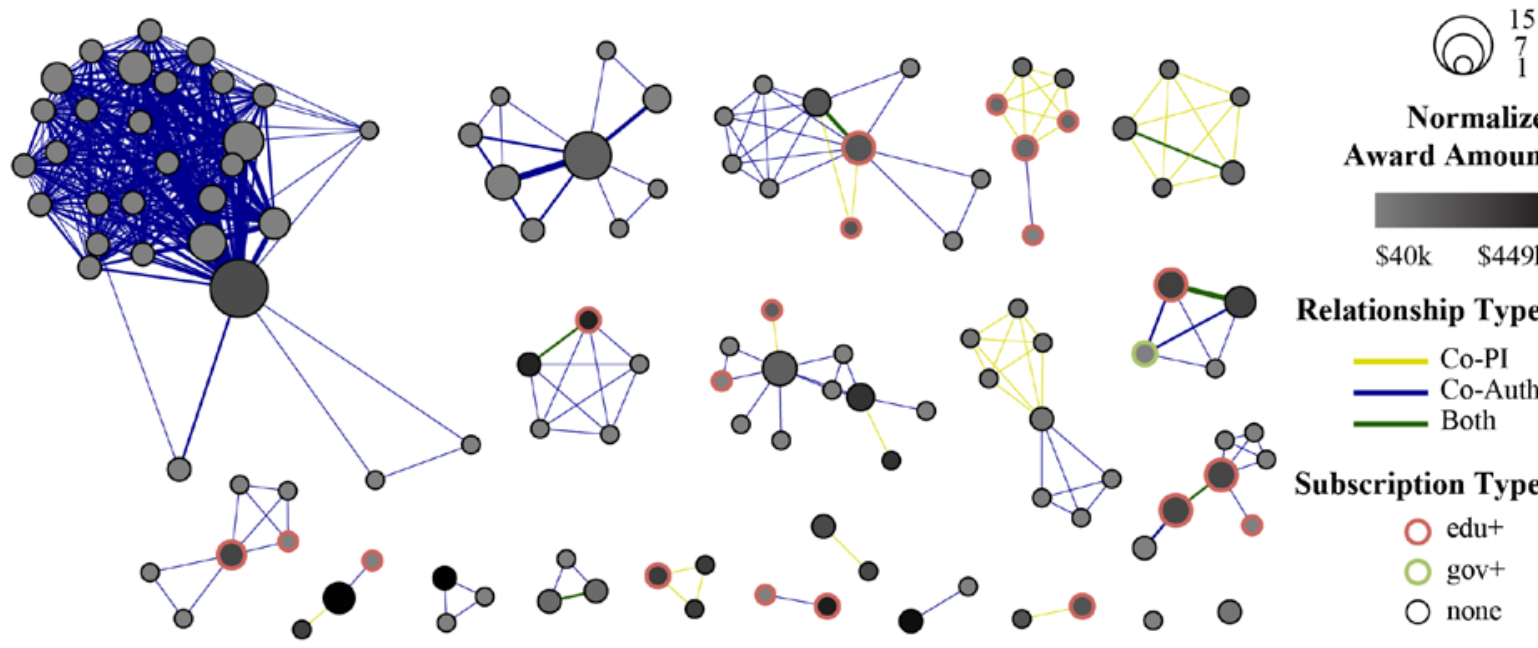

Figure 3. Collaboration network, including all awards with available publication data.

Green edges in the network are comparatively rare. There are only six instances of individuals sharing both relationship types. This particular set of awards includes three awards with five investigators each, but even among these it appears uncommon for investigators to co-author papers. Though these results are tempered by the sparseness of data, they offer the opportunity to explore these interactions in a more complete data set. If PIs largely do not share authorship ties, there may be a division of labor where an investigator "team" is engaging in predominantly isolated projects.

\section{Activity Within the Online Community}

Until the publication and citation data for the field mature, it may be possible to uncover evidence of interaction and community structure within other community resources, like the SciSIP listserv. To explore solicitation and response with the community, each listserv message was assigned to a thread, which in this context is defined as a series of one or more messages that relate to each other. The 919 messages belong to 426 threads, for an average of 2.16 messages per thread. Messages without replies are considered threads of only a single message; there were 322 such threads. The remaining 104 threads contained 597 messages, for an average of 5.74 messages for multi-message threads. The average length of the threads is 2.69 days over all threads and 7.93 days when excluding single message threads.

The content analysis of the 425 uncorrupted thread initiation messages identified four primary types of messages: (1) announcement of a resource (e.g., papers, tools, websites) or event (e.g., conference, workshop) of interest, (2) request for submissions to a formal solicitation (e.g., CFP, RFA), (3) request for feedback or input on a posed question or topic (e.g., looking for literature on a particular subject), and (4) other (e.g., subscription attempts, technical matters). Each thread was further analyzed by coding the number of messages in the thread, the length of time between the first message and the last message, the affiliation of the 
individual who sent the first message of the thread, the number of individuals who sent responses to the thread, the affiliations of the individuals who responded, and the type of message that began the thread. Summary statistics of the coded threads are available in Tables 5 through 8.

Table 5 shows the responsiveness of threads (or the ability for threads to elicit response), subdivided by initiation message type. As might be expected, requests for feedback are over twice as prevalent in the subgroup of messages that received a response as they are in the entire population of messages. That is, given how often people request feedback, we would expect about $13 \%$ of the messages with responses to be requests for feedback. The observed proportion of almost 30\% indicates that explicit requests for feedback are successful in improving the likelihood of a response.

Table 5. The number of message threads starting with a message of each type, further subdivided by responsiveness.

\begin{tabular}{l|cccc}
\hline & All Threads & $\begin{array}{c}\text { With } \\
\text { Response }\end{array}$ & $\begin{array}{c}\text { Without } \\
\text { Response }\end{array}$ & $\begin{array}{c}\text { Average \# of } \\
\text { Messages in Thread }\end{array}$ \\
\hline resource or event of interest & $261(61.4 \%)$ & $49(47.1 \%)$ & $212(66.0 \%)$ & 1.6 \\
request for submissions & $91(21.4 \%)$ & $19(18.3 \%)$ & $72(22.4 \%)$ & 1.5 \\
request for feedback & $57(13.4 \%)$ & $31(29.8 \%)$ & $26(8.1 \%)$ & 6.2 \\
other & $16(3.8 \%)$ & $5(4.8 \%)$ & $11(3.4 \%)$ & 1.5 \\
Total & $425(100 \%)$ & $104(100.0 \%)$ & $321(100.0 \%)$ & 2.2 \\
\hline
\end{tabular}

In tables 6 and 7 below, high values in each row are colored green, and low values are colored red. Suggestions of resources or events make up a larger proportion of the initiation messages from com+ than any other group of senders. Requests for submissions most often come from edu + or gov + senders. Requests for feedback are a big proportion of the messages from org+ senders. Trends for other messages are less clear because of the small number of threads initiated by these types of messages.

Table 6. The number of message threads starting with a message of each type, further subdivided by the institutional affiliation of the initiator.

\begin{tabular}{l|ccccc}
\hline & All Threads & com + & edu+ & gov+ & org $^{+}$ \\
\hline resource or event of interest & $261(61.4 \%)$ & $15(78.9 \%)$ & $113(62.8 \%)$ & $119(60.1 \%)$ & $14(50.0 \%)$ \\
request for submissions & $91(21.4 \%)$ & $1(5.3 \%)$ & $42(23.3 \%)$ & $43(21.7 \%)$ & $5(17.9 \%)$ \\
request for feedback & $57(13.4 \%)$ & $1(5.3 \%)$ & $20(11.1 \%)$ & $29(14.6 \%)$ & $7(25.0 \%)$ \\
other & $16(3.8 \%)$ & $2(10.5 \%)$ & $5(2.8 \%)$ & $7(3.5 \%)$ & $2(7.1 \%)$ \\
Total & $425(100 \%)$ & $19(100 \%)$ & $180(100 \%)$ & $198(100 \%)$ & $28(100 \%)$ \\
\hline
\end{tabular}

Table 7. The responsiveness of messages, further subdivided by the institutional affiliation of the initiator.

\begin{tabular}{l|lllll}
\hline & \multicolumn{1}{c}{ All Messages } & \multicolumn{1}{c}{ com +} & \multicolumn{1}{c}{ edu+ } & \multicolumn{1}{c}{ gov+ } & \multicolumn{1}{c}{ org $^{+}$} \\
\hline initiations with no response & $322(35.0 \%)$ & $18(23.4 \%)$ & $141(34.3 \%)$ & $143(39.3 \%)$ & $20(29.9 \%)$ \\
initiations with response & $104(11.3 \%)$ & $1(1.3 \%)$ & $39(9.5 \%)$ & $55(15.1 \%)$ & $9(13.4 \%)$ \\
messages that do not initiate & $493(53.6 \%)$ & $58(75.3 \%)$ & $231(56.2 \%)$ & $166(45.6 \%)$ & $38(56.7 \%)$ \\
Total & $919(100.0 \%)$ & $77(100.0 \%)$ & $411(100.0 \%)$ & $364(100.0 \%)$ & $67(100.0 \%)$ \\
\hline
\end{tabular}


Table 7 shows the responsiveness of messages from each affiliation type. Senders with gov + affiliations make up the largest proportion of initiations with and without a response and thus send more initiations than even edu+ senders, who have the largest raw number of messages. Senders with com+ affiliations are notably lacking in any initiations, but they are well represented in responses. Senders with org+ messages send messages in proportions that are closer to the proportions over the entire population.

Table 8 shows the top ten most active threads. One early initiation received 65 responses in just over a week. The activity level drops off quickly from that peak, and most threads have a length of only a few days. Eight of the top ten threads were initiated by senders with gov + affiliations, and all but one was initiated by an explicit request for feedback.

Table 8. The top ten most active threads.

\begin{tabular}{|c|c|c|c|c|}
\hline Subject & $\begin{array}{l}\text { Number of } \\
\text { Messages } \\
\text { in Thread }\end{array}$ & $\begin{array}{c}\text { Initiator } \\
\text { Affiliation }\end{array}$ & $\begin{array}{c}\text { Type of Initiation } \\
\text { Message }\end{array}$ & $\begin{array}{c}\text { Length of } \\
\text { Thread } \\
\text { (in Days) }\end{array}$ \\
\hline $\begin{array}{l}\text { Congressional and Executive branch } \\
\text { requests for information... }\end{array}$ & 66 & gov + & request for feedback & 8 \\
\hline Illustration of Innovation Ecology & 33 & gov+ & request for feedback & 14 \\
\hline need a reference & 19 & gov + & request for feedback & 3 \\
\hline Wiki vs blog vs ??? & 16 & gov + & request for feedback & 2 \\
\hline Question from the executive branch & 14 & gov + & request for feedback & 4 \\
\hline US S\&T book/article query? & 13 & edu+ & request for feedback & 2 \\
\hline $\begin{array}{l}\text { Energy Innovation Systems from the } \\
\text { Bottom Up... }\end{array}$ & 12 & edu+ + & resource or event of interest & 2 \\
\hline Help re citations data & 12 & gov + & request for feedback & 2 \\
\hline Federal Innovation Inducement Prizes & 12 & gov+ & request for feedback & 2 \\
\hline $\begin{array}{l}\text { FW: Collaboration - Achieving Better } \\
\text { Results by Working Together }\end{array}$ & 12 & gov + & request for feedback & 2 \\
\hline
\end{tabular}

Figure 4 gives several views of thread activity over time. The images on the left summarize the activity of those who initiate threads. On the top left is a visualization of the number of threads that are initiated by senders of each affiliation, using messages of each type. Over time, threads initiated by announcing a resource or event of interest become more prevalent, especially for edu+ and gov+ initiators. There is an early spike for threads that request feedback, but those stabilize to a lower level than announcements and requests for submissions. In slight contrast, the number of individual senders who initiate shows that there is some repetition in initiators. For March 2010, the 12 threads initiated by edu+ senders come from nine senders. Overall, however, the trends are similar, suggesting that more than just a few individuals are initiating threads. (A counter-example might be the requests for submissions initiated by gov + senders in August and October of 2010. The numbers of threads for these months are similar to the number for September, but the sender circles are much smaller than that of September.)

The right side of Figure 4 shows the activity of those responding to the thread initiations. Note again that only 104 threads received any response. The top right image in Figure 4 shows the diversity of responders to threads from a particular affiliation in a particular month. Requests for feedback from edu+ or gov+ initiators, particularly in the early months, tend to get responses from each of the four affiliation groups (com+, edu+, gov + , and org + ). Also, while com+ senders do initiate threads with each type of initiation message, only one thread (a resource of interest in March 2010) receives any response. High respondent diversity and a 


\section{Thread Activity by Type of Initiation Message and Affiliation of Sender, Over Time}

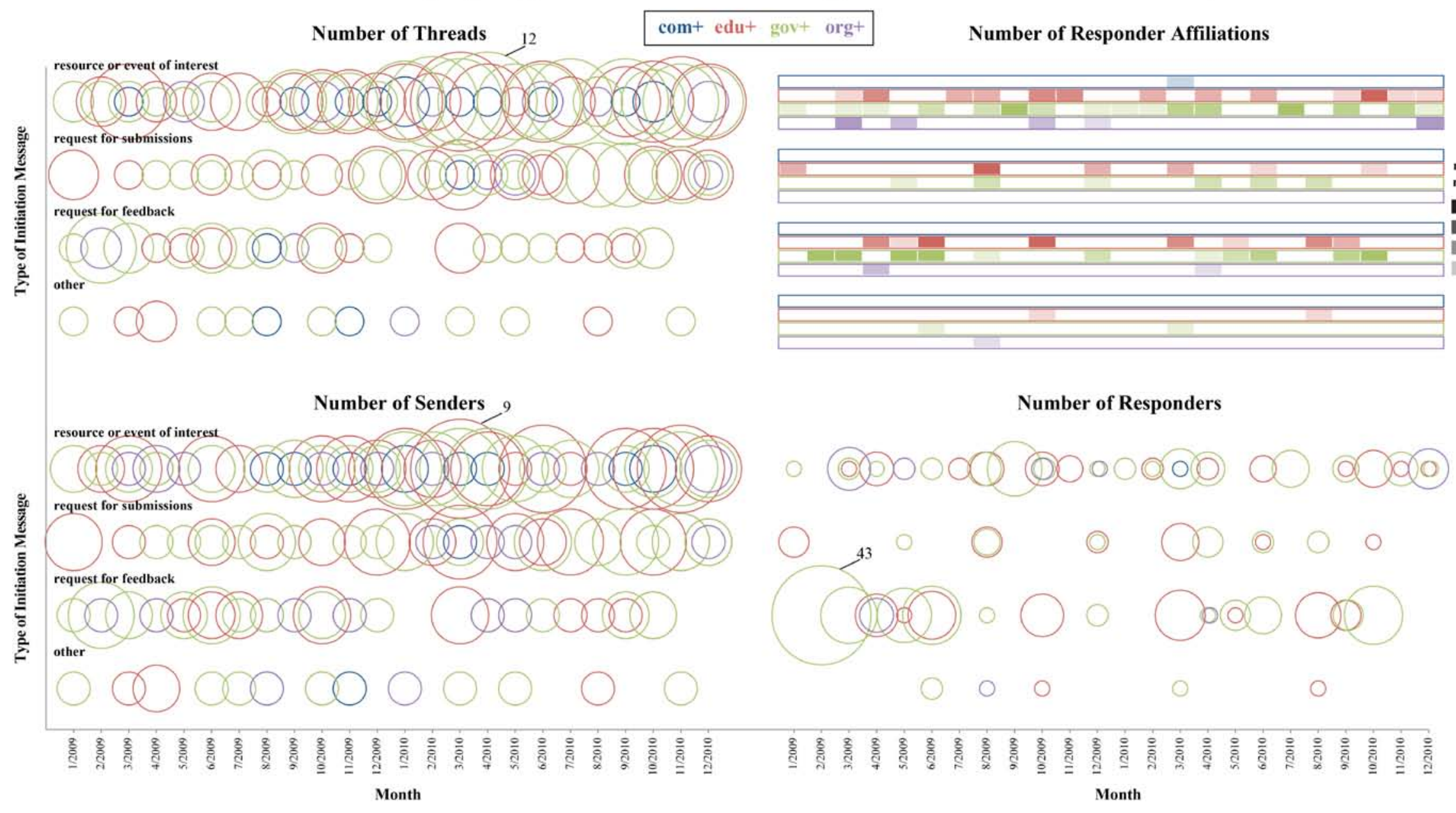

Figure 4. Message activity, including number of threads, senders, responder affiliations, and responders.

Each month has data points for each type of initiation message and each affiliation of the thread initiator. 
high response count might be expected from explicit requests for feedback, and this supposition does seem to be supported by the data.

Figure 5 shows the network of initiations and responses from the 919 listserv messages. Messages that do not initiate a thread (i.e., all subsequent messages in a thread after it is initiated) are treated as responses to the initiation message, although they may in fact be responses to a response. This convention is adopted to visualize the activity that the initiation message prompts from the community, as opposed to the precise flow of information through the sender network. For example, the directed edges from one individual to another could be seen as responses that are drawn (directly or indirectly) from members of the community by the initiator. The indegree of a node is thus a measure of the individual's ability to draw many different individuals into the conversation. Outdegree of a node indicates an individual's willingness to engage with many different initiators. Nodes are color-coded by total degree.

\section{Email Response Network}
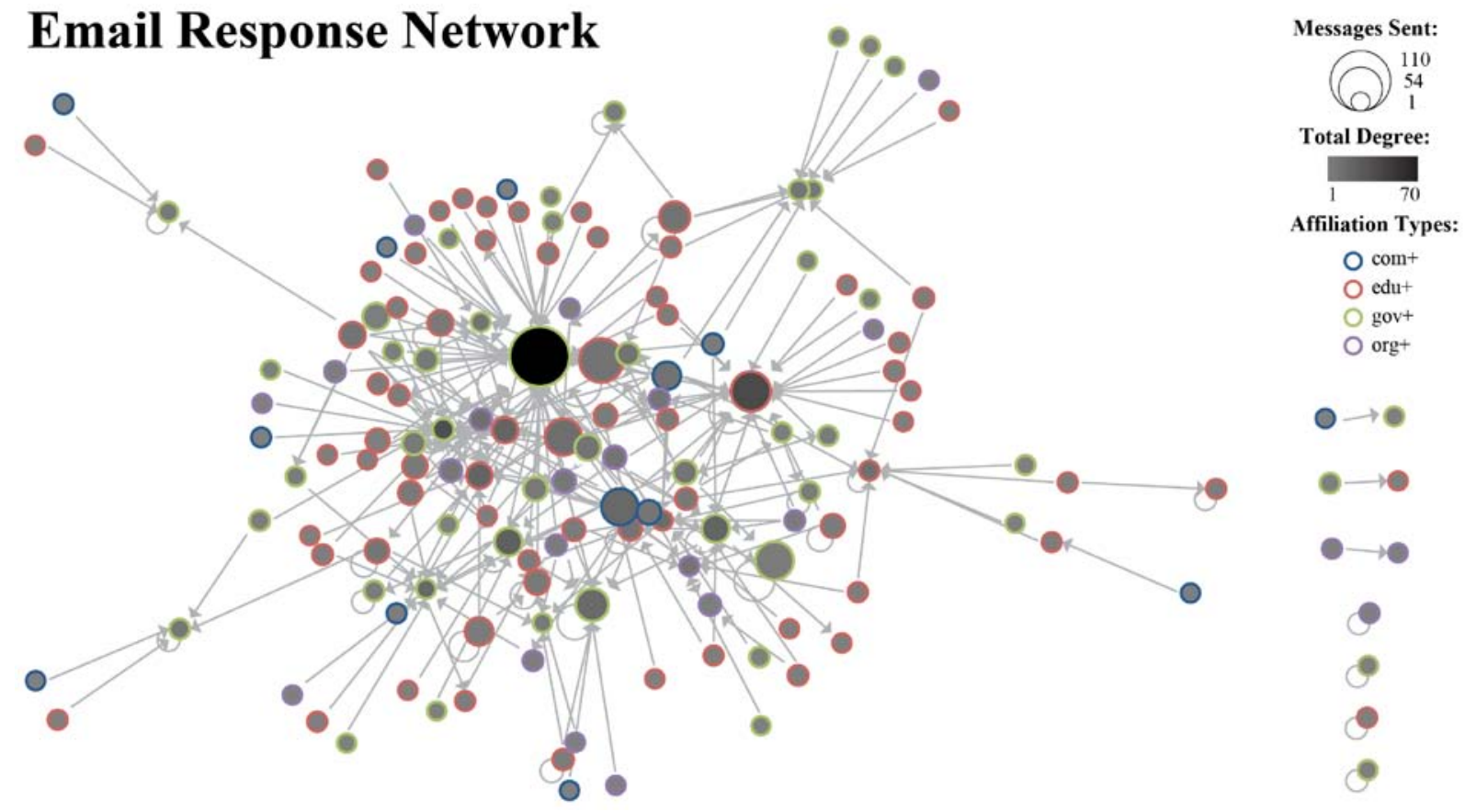

Figure 5. Email response network. Nodes are individuals who sent messages to the listserv. A directed link points from a responder to the person who initiated the thread.

The size coding of the nodes in the email response network represents the number of messages sent by the individual. The node outline color indicates the affiliation of the node. Each of the four affiliation types is active in the primary component of the network. The network shows many roles of individuals and many ways of participating in the discussion, from broadcasters, who send announcements and updates but do not spark or fuel discussion, to those who serve brokerage roles and those who send only a few messages but elicit responses from a variety of others. The interconnectedness of the participants and the sheer number of links created supports the interpretation of the listserv as an environment where individuals from many different professions actively engage in a productive dialogue.

\section{Discussion}

Though the highly interdisciplinary Science of Science and Innovation Policy community is still young and resists widespread bibliometric analysis, it is possible to use network and content analysis methods to describe different facets of the community for a more comprehensive view of how the field is developing. This research shows that while the analysis of formal collaborations suggests some degree of isolation among award recipients, 
many of those recipients do participate in a diverse and active online community. On the other hand, many of the members of the online community (e.g., those from other countries, those who are not affiliated with educational or research institutions) are absent from the traditional bibliometric studies, and though informal communication venues do not serve the same purposes as formal venues, a richer understanding of the research community as a whole can nonetheless contribute to ongoing policy and infrastructure decisions related to the field. In a field where connections to policy makers and industry professionals are crucial to the success of researchers and vice versa, it is essential to be able to describe these informal interactions and analyze how they complement research activities.

Though the limitations of data sparseness and small scope prevent broader generalizations or predictions, the methods explored here sketch the rough boundaries of the community and offer suggestions for future research on SciSIP and for new mapping studies. With more robust publication data, additional bibliometric analyses can be incorporated and compared to other mapping studies. To increase the scalability of the content analysis, some automated text mining might be applied to email corpora both to identify thread assignment (e.g., using quoted material in addition to subject heading) and to code messages, perhaps by identifying and locating key phrases or other statistical markers. This paper takes the first early step toward mapping the SciSIP community, but as the community continues to grow and change, so too must the methods of description and the questions around which the explorations revolve.

\section{Acknowledgments}

This work is funded in part by the James S. McDonnell Foundation, the National Science Foundation under award SBE-0738111, and the National Institutes of Health under award NIH U24RR029822. Any opinions, findings, and conclusions or recommendations expressed in this material are those of the author(s) and do not necessarily reflect the views of the National Science Foundation.

\section{References}

Donath, J., Karahalios, K., \& Viegas, F. (1999). Visualizing conversation. Journal of ComputerMediated Communication, 4(4). Retrieved January 15, 2011 from: http://jcmc.indiana.edu/vol4/issue4/donath.html

Milojević, S. (2010). Power law distributions in information science: Making the case for logarithmic binning. Journal of the American Society for Information Science and Technology, 61(12), 24172425.

National Science Foundation Award Search. (2008). Retrieved January 15, 2011 from: http://www.nsf.gov/awardsearch/

$\mathrm{Sci}^{2}$ Team. (2009). Science of Science (Sci $\left.{ }^{2}\right)$ Tool. Indiana University and SciTech Strategies. Retrieved September 28, 2010 from: http://sci2.cns.iu.edu

Science of Science and Innovation Policy. (2010). Retrieved January 15, 2011 from: http://www.nsf.gov/funding/pgm_summ.jsp?pims_id=501084\&org=sbe

Weingart, S., Guo, H., Börner, K., Boyack, K. W., Linnemeier, M. W., Duhon, R. J., Phillips, P. A., Tank, C., \& Biberstine, J. (2010). Science of Science (Sci2) tool user manual. Cyberinfrastructure for Network Science Center, School of Library and Information Science, Indiana University, Bloomington. Retrieved January 15, 2011 from: http://sci2.wiki.cns.iu.edu

Welser, H. T., Gleave, E., Fisher, D., \& Smith, M. (2007). Visualizing the signatures of social roles in online discussion groups. Journal of Social Structure, 8(2). Retrieved January 15, 2001 from: http://www.cmu.edu/joss/content/articles/volume8/Welser/

Xiong, R., \& Donath, J. (1999). PeopleGarden: creating data portraits for users. In Proceedings of the 12th annual ACM symposium on User interface software and technology (UIST '99), ACM, New York, NY, 37-44. 